\title{
Limited Experienced Happiness or Unlimited Expected Utility, What About the Differences?
}

\author{
Review of Happiness Around the World; the Paradox of Happy \\ Peasants and Miserable Millionaires by Carol Graham Oxford \\ University Press, New York, 2009, ISBN 978-0-19-954905-4
}

\section{Jan Cornelis Ott}

Published online: 13 July 2010

(C) The Author(s) 2010. This article is published with open access at Springerlink.com

\begin{abstract}
Happiness and utility are two types of subjective well-being, but measured in different ways. Happiness is measured by asking people questions about their subjective appreciation of their life as a whole. Utility is measured by an assessment of their subjective priorities, as revealed in their actual behaviour. Both methods have specific pros and cons and additional value. These methodological issues are important in an epistemological way: how to obtain knowledge about subjective well-being. There are, however, also three important ontological differences between happiness and utility in the actual nature of these phenomena in reality. (1) Happiness depends on available market and nonmarket commodities and living-conditions; utility depends only on available marketcommodities. (2) Happiness is about experienced well-being, utility is about expected well-being. (3) Happiness is limited because it is related to the fulfilment of a limited number of needs, utility is unlimited because behaviour always reveals preferences in terms of expected well-being. Economists and happiness-researchers tend to neglect the last two differences. Their analysis, the analysis of Carol Graham included, could gain strength if more attention would be paid to these last two differences.
\end{abstract}

Keywords Subjective well-being · Utility $\cdot$ Revealed preferences · Happiness · Self-reported happiness · Needs and wants

\section{Introduction}

Carol Graham is an economist and the author of numerous books and articles on poverty, inequality, and novel measures of well-being. Her latest book "Happiness around the World" is interesting and very informative. She evaluates very accurately the relations between happiness and variables like income, health, marital status and employment and applies sophisticated statistical procedures to assess possible causality in such relations.

J. C. Ott (西)

Erasmus University Rotterdam, Rotterdam, The Netherlands

e-mail: jan.ott@planet.nl 
Graham is cautious but optimistic about the importance of happiness-research for policymakers.

\section{Graham's Book}

\subsection{Graham's Inventory of Causes and Consequences of Happiness}

Graham identifies income, age, health and marital status as important determinants for the level and the distribution of happiness in general. The impact of other variables on happiness, like gender, education and employment, depends on contextual factors like gender rights, returns on education and the position of retired people and the self-employed. Subjective variables, like optimism, adaptation, and the acceptance of inequality, help to explain some irregularities. Graham demonstrates that several factors have a two-way causal relationship with happiness; having an impact on happiness but simultaneously being influenced by it. In a panel-study in Russia she evaluates such relations by using the unexplained or residual individual happiness in 1995 as an independent variable to predict developments after 1995. The residual happiness appears to predict future income and health, but not getting married or divorced, or becoming unemployed. The positive impact of happiness on income and health underlines the social-economic importance of happiness.

\subsection{Graham's Inventory of Paradoxes in the Relationship Between Income and Happiness}

The relation between income and happiness gets a lot of attention in Graham's book. Wealthier people are in general happier than poorer ones, but Graham describes three paradoxes.

(a) The paradox of the unhappy economic growth: Countries with higher GDP per capita have higher levels of happiness, but controlling for these levels of GDP per capita individuals have lower levels of happiness in countries with positive growth rates (research by Eduardo Lora and collaborators 2009). The accompanying dislocation of rapid growth apparently undermines the positive effect of higher income levels.

(b) The paradox of the happy peasant and the frustrated achiever: This happens for instance in China where urban migrants are materially better off than they were before they migrated, but they report higher levels of frustration. Once they migrate their reference norm quickly becomes other urban residents rather than their previous peers in rural areas.

(c) The paradox of the optimistic poor people: Within countries wealthier respondents are happier, but there is clearly an 'optimism bias' in the responses of the poorest respondents. Their expectations are very low and the impact of misery on their happiness is therefore rather modest. Even the substantial income-inequality in Latin America is not matched by a comparable difference in satisfaction with the material and economic quality of life.

Relative income within nations seems to matter for happiness. This is one of the explanations for the Easterlin paradox: relative income matters for individual happiness within societies, but average happiness is rather insensitive for economic growth if some minimal GDP-level per capita is reached. An alternative explanation is adaptation of expectations. Expectations rise in good conditions, like high levels of freedom, and go down in bad conditions, like high levels of crime or corruption. Downward adaptation is an 
important survival mechanism at times of adversity. Rising expectations may have provided impetus to rising ambitions and to the remarkable progress humanity has made in areas such as technology and health. In Graham's view it is difficult to judge whether rising expectations or downward adaptations are good or bad things; they are likely part of human nature.

\subsection{Graham's Inventory of Policy Implications of Happiness-Research}

In the last chapter Graham evaluates the policy-implications of happiness-research. What can policymakers take from the findings so far? Graham makes some cautionary remarks but she also presents some positive conclusions.

(a) Cautionary remarks: A fundamental problem is whether happiness should be a policy objective in the first place. Are happy people successful or complacent? There is evidence that happy people perform better in the labour market and that they are healthier. But the evidence also suggests that there is a top limit to this. People who score a 10 are successful, but people who score somewhat lower (7-9) are more successful. A related problem in Graham's view is the importance of happiness as a purpose, relative to alternative purposes like growth, policy reforms, and fiscal stability. There are temporal considerations as well. Many reforms make people unhappy in the short term but produce more happiness in the long run.

(b) Positive conclusions: Happiness surveys have great promise in Graham's view for helping to understand a variety of phenomena which cannot be explained by standard optimal choice or revealed preferences approaches. Two sets of questions come to the fore. The first is the welfare effects of macro and institutional arrangements that individuals are powerless to change, such as macroeconomic volatility, inequality, or weak government structures. In such situations people, and in particular the poor, are unable to express their preferences. The second set of questions is those in which behaviours are not the result of preferences but of norms, addiction, self-control problems and undue expectations. If people have low expectations for their own and their children's future their decisions on any number of fronts, ranging from investing in their children's education to saving and public health attitudes, could be compromised. Another promise for happiness surveys is in the understanding of non-income variables, such as health, education, employment status, gender rights and environment. In Graham's view happiness can ultimately complement standard income-based measures as a measure for the quality of life. In the same way that GDP allows us to track economic growth within and across countries, national-well-being measures like happiness provide a complementary tool for assessing welfare trends.

\section{My Comments}

I find that happiness can be discussed in three ways: in an epistemological way, in an evaluative or normative way, or in an ontological way. The epistemological discussion is about how we can obtain knowledge about happiness, the evaluative discussion is about happiness as a moral value or policy objective, and the ontological discussion is about the nature of happiness in reality. Graham's book is primarily epistemological: but hardly evaluative or ontological. She is positive about happiness as a measure for the quality of life and she identifies some specific opportunities to use happiness in situations where 
revealed preferences are inadequate as a source of information. ${ }^{1}$ Her book is hardly evaluative; she only makes some evaluative remarks about happiness as a policy objective. Her book is not very ontological either, because there are at least three important differences between neoclassical utility and happiness, and she only makes some remarks about the first difference. The three differences are:

1. happiness is a more comprehensive indicator than utility,

2. happiness is about experienced well-being, utility is about expected well-being,

3. happiness is limited, utility is unlimited.

Difference 1: happiness is more comprehensive: In Graham's view the study of happiness is part of a more general move in economics that challenges the narrow neoclassical assumptions that people maximize utility. Happiness economics relies on a more expansive notion of utility, including interdependent utility functions, procedural utility, and the interaction between rational and non-rational influences in determining economic behaviour. At this point she recognizes happiness as a more comprehensive indicator for subjective well-being than the neoclassical concept of utility.

Happiness depends not only on goods and services available on the market, but also on non-market commodities and living conditions. Graham mentions some examples of non-market-commodities: health, gender rights and environment. She also might have mentioned freedom, personal autonomy, social trust and companionship, as put forward by Putman (2000) and Lane (2000).

Difference 2: happiness is about experienced well-being, utility is about expected wellbeing: Another difference is that happiness is based on actual experienced well-being (ex post or current), while utility is based on expected well-being (ex ante) because choices are based on expectations. The difference between experiences and expectations is important even though they can be highly interconnected. Expectations can arise from hearsay, papers, books, soaps and imagination, but are also highly dependent on experiences. Experiences of subjective well-being, on the other hand, can be highly influenced by relevant expectations. In the national shipping museum in Antwerp I learned about the happiness of people who immigrated by ship to the US around 1900. Many of them left a difficult life behind them, with poverty and repression, and the actual conditions on the ships were far from pleasant. These people were nevertheless very happy on the ship, because they expected a better life. The contrast between their experienced past and their expected future created strong emotions. Even if the 'best-worst' question would have been used they would have reported high happiness levels. This question is formulated as follows: Suppose we say that the top of the ladder represents the best possible life for you and the bottom of the ladder represents the worst possible life for you. Where on this ladder do you feel you personally stand at the present time (0-10). Strictly speaking the qualification 'at the present time' invites people to disregard their expectations, but people probably disregard this invitation. Even with this question the immigrants on the ship probably would have reported high happiness levels. On the other hand, however, most of our daily experiences take place without any specific expectations. At this point we may posit that, in the interaction between experiences and expectations, experience will be the dominant factor, and probably becomes more dominant when we get older. This dominancy of actual experience is also visible in the strong relation between happiness and actual conditions like safety and wealth. Peasants may be happy occasionally, and

\footnotetext{
${ }^{1}$ See Ott (2010) for a systematic inventory of the differences between revealed and stated preferences and self-reported happiness as sources of information.
} 
millionaires miserable, but empirical data tell a convincing story about this relation in general. We have to keep in mind, however, that expectations can be an interfering factor. The relationship between actual conditions on the one hand, and happiness or utility on the other, can be rather loose in specific situations by the impact of expectations. ${ }^{2}$ The gap between conditions and happiness will be smaller usually than the gap between conditions and utility. In that respect happiness is a more representative indicator for the 'objective' quality of life.

Difference 3: happiness is limited, utility is unlimited: Utility has no maximum and it can only to be measured at an ordinal level. This is consistent with economic theory: human wants are endless and are always expressed in choices people make, as revealed in their behaviour. These choices are always based on expected well-being and always produce additional utility. There will never be any limit. A dominant assumption in happiness-research on the other hand is that happiness depends on the gratification of a limited number of basic needs. ${ }^{3}$ In the terminology of Veenhoven (2009): 'Needs are inborn and universal while 'wants' are acquired and can be variable across cultures'. Happiness will reach a maximum level if inborn needs are satisfied. This assumption is supported by the fact that in wealthy nations average happiness is very stable at a high level, also in periods of rapid economic growth. ${ }^{5}$ There is, however, a complication: it is one of the basic needs to use and further develop inborn or innate capabilities. ${ }^{6}$ People always want to be active and creative, and they always need challenges. Even if they have reached their maximum level of happiness they will produce utility, in order to stay at that maximum.

\section{Conclusion}

Graham's book is a great contribution to our knowledge of subjective well-being, but her analysis would have gained more strength if she would have paid more attention to the second and third difference between happiness and utility. One example: if happiness has indeed a maximum the positive contribution of any factor, be it objective like wealth or subjective like optimism, is inevitably characterized by diminishing returns. This implies a

\footnotetext{
2 Warning: expectations about happiness can be very wrong, as has been nicely demonstrated by Daniel Gilbert is his 'Stumbling on happiness' (2007).

3 A well-known typology is presented by A. Maslow: (1) physiological, (2) safety, (3) love/belonging, (4) esteem, (5) self-actualization. A more sophisticated typology is presented by Wentholt (1980) in terms of motivation:

(1) Organic basic motivations, (1a) based on homeostatic principles (hunger, thirst, sexuality), (1b) based on stimulation-seeking (intrinsic motivation and affection). Wentholt additionally presents some complications in the actual dynamics of such motivations by the (typical human) consciousness, like consciousness of our emotions, existential conditions and individual identity.

4 As reported by Nettle (2005) this distinction between basic needs and wanting, or between liking and wanting as he puts it, hangs together with the fact that we have different sub-systems in our brain to regulate liking and wanting.

5 As a consequence happiness can be measured at a cardinal level with numerical scales, like the 0-10 ladder-scale as it is used by Gallup. This is possible because respondents are able to divide the range between zero and the maximum in equal parts, representing comparable differences in their subjective appreciation. This cardinal option is not available in the measurement of utility, because utility has no maximum.

6 In Maslow's typology self-actualization, in Wentholt's typology stimulation-seeking motivations and in particular intrinsic motivation.
} 
different reality and requires a different analysis. It also presents an additional explanation for the Easterlin paradox. And what about policy-implications? If there is indeed a maximum to happiness, and if this maximum is achieved in nations by a reasonable level of material wealth, individual freedom, security, healthcare, and an accepted level of inequality, would this be the end of politics and policy? Obviously not. If people are happy they will try to keep it up and in order to keep it up they will still have to be active and creative. They will, in economic language, still create more utility. Some basic realities will be different, however. Economic growth will no longer be an instrument for additional happiness, but only a consequence of the fact that people need to be active. Perhaps our wants are nowadays manipulated and blown up by commercial interests, but we cannot do without them. Such conclusions are interesting, also in normative and evaluative discussions about politics and policy. Perhaps the problems of unhappy people deserve a higher priority than the problems of the happy ones, and perhaps all happiness-problems can be solved simultaneously!

Open Access This article is distributed under the terms of the Creative Commons Attribution Noncommercial License which permits any noncommercial use, distribution, and reproduction in any medium, provided the original author(s) and source are credited.

\section{References}

Gilbert, D. (2007). Stumbling on happiness. New York: Vintage Books, Random House.

Lane, R. (2000). The loss of happiness in market democracies. New Haven, London: Yale University Press. Lora, E., \& Chapero, C. (2009). The conflictive relationship between satisfaction and income. In C. Graham \& E. Lora (Eds.), Paradox and perception: Measuring quality of life in Latin America. Washington: The Brooking Institution and the Inter-American Development Bank.

Nettle, D. (2005). Happiness; the science behind your smile. Oxford, UK: Oxford University Press.

Ott, J. C. (2010). Happiness, economics and public policy; a critique. Review article on 'Happiness, economics and public policy' by Helen Johns and Paul Ormerod. Journal of Happiness Studies, 11, nr. 1.

Putman, R. (2000). Bowling alone: The collapse and revival of American community. New York: Simon\& Schuster.

Veenhoven, R. (2009). How do we assess how happy we are? In A. K. Dutt \& B. Radcliff (Eds.), Happiness, economics and politics: Towards a multi-disciplinary approach, Chap. 3 (pp. 45-69). Cheltenham, UK: Edward Elger Publishers.

Wentholt, R. (1980). Reader motivatie-leer (Motivation-theory). 